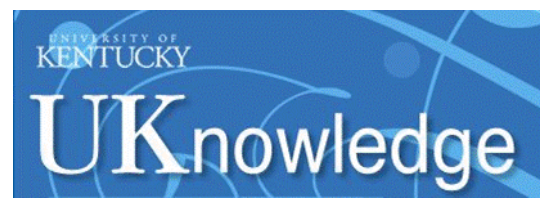

University of Kentucky

UKnowledge

\title{
Frameless Image-Guided Radiosurgery for Trigeminal Neuralgia
}

Lisa B. E. Shields

Norton Healthcare

Todd S. Shanks

Norton Healthcare

Andrew J. Shearer

University of Kentucky, ajsh225@uky.edu

Lauren A. Shelton

University of Kentucky, laurenshelton@uky.edu

Brent J. Shelton

University of Kentucky, brent.shelton@uky.edu

See next page for additional authors

Follow this and additional works at: https://uknowledge.uky.edu/markey_facpub

Part of the Neurology Commons, and the Oncology Commons

Right click to open a feedback form in a new tab to let us know how this document benefits you.

\section{Repository Citation}

Shields, Lisa B. E.; Shanks, Todd S.; Shearer, Andrew J.; Shelton, Lauren A.; Shelton, Brent J.; Howe, Jonathan; Coons, James M.; Plato, Brian; and Spalding, Aaron C., "Frameless Image-Guided Radiosurgery for Trigeminal Neuralgia" (2017). Markey Cancer Center Faculty Publications. 90.

https://uknowledge.uky.edu/markey_facpub/90

This Article is brought to you for free and open access by the Markey Cancer Center at UKnowledge. It has been accepted for inclusion in Markey Cancer Center Faculty Publications by an authorized administrator of UKnowledge. For more information, please contact UKnowledge@lsv.uky.edu. 


\section{Frameless Image-Guided Radiosurgery for Trigeminal Neuralgia}

Digital Object Identifier (DOI)

https://doi.org/10.4103/2152-7806.207119

\section{Notes/Citation Information}

Published in Surgical Neurology International, v. 8, p. 87-94.

(C) 2017 Surgical Neurology International

This is an open access article distributed under the terms of the Creative Commons AttributionNonCommercial-ShareAlike 3.0 License, which allows others to remix, tweak, and build upon the work non-commercially, as long as the author is credited and the new creations are licensed under the identical terms.

\section{Authors}

Lisa B. E. Shields, Todd S. Shanks, Andrew J. Shearer, Lauren A. Shelton, Brent J. Shelton, Jonathan Howe, James M. Coons, Brian Plato, and Aaron C. Spalding 


\title{
Original Article
}

\section{Frameless image-guided radiosurgery for trigeminal neuralgia}

\author{
Lisa B. E. Shields ${ }^{1,2}$,Todd S. Shanks ${ }^{1,2}$, Andrew J. Shearer ${ }^{3}$, Lauren A. Shelton ${ }^{3}$, Brent J. Shelton ${ }^{3}$, \\ Jonathan Howe ${ }^{2,4}$, James M. Coons ${ }^{2,4}$, Brian Plato ${ }^{1}$, Aaron C. Spalding ${ }^{2,4}$ \\ ${ }^{1}$ Norton Neuroscience Institute, ${ }^{2}$ The Brain Tumor Center, Norton Healthcare, Louisville, ${ }^{3}$ Markey Cancer Center, University of Kentucky, Lexington, \\ ${ }^{4}$ The Norton Cancer Institute Radiation Center and Kosair Children's Hospital, Louisville, Kentucky, USA \\ E-mail: Lisa B.E. Shields - LBES@earthlink.net;Todd S. Shanks -Todd.Shanks@nortonhealthcare.org; Andrew J. Shearer - Ashearer@kcr.uky.edu; \\ Lauren A. Shelton - Lauren.Shelton@uky.edu; Brent J. Shelton - Bshelton@kcp.uky.edu; Jonathan Howe - Jonathan.Howe@nortonhealthcare.org; \\ James M. Coons - JamesMichael.Coons@nortonhealthcare.org; Brian Plato - Brian.Plato@nortonhealthcare.org; *Aaron C. Spalding - acspalding1@gmail.com \\ *Corresponding author
}

Received:21 October $16 \quad$ Accepted: 30 December $16 \quad$ Published:26 May 17

\begin{abstract}
Background: Frameless image-guided radiosurgery (IGRS) is a safe and effective noninvasive treatment for trigeminal neuralgia (TN). This study evaluates the use of frameless IGRS to treat patients with refractory TN.

Methods: We reviewed the records of 20 patients diagnosed with TN who underwent frameless IGRS treatments between March 2012 and December 2013. Facial pain was graded using the Barrow Neurological Institute (BNI) scoring system. The initial setup uncertainty from simulation to treatment and the patient intrafraction uncertainty were measured. The median follow-up was 32 months.

Results: All patients' pain was BNI Grade IV or V before the frameless IGRS treatment. The mean intrafraction shift was $0.43 \mathrm{~mm}(0.28-0.76 \mathrm{~mm})$, and the maximum intrafraction shift was $0.95 \mathrm{~mm}(0.53-1.99 \mathrm{~mm})$. At last follow-up, $8(40 \%)$ patients no longer required medications (BNI 1 or 2$), 11(55 \%)$ patients were pain free but required medication (BNI 3), and $1(5 \%)$ patient had no pain relief (BNI 5). Patients who did not have prior surgery had a higher odds ratio for pain relief compared to patients who had prior surgery $(14.9, P=0.0408)$.

Conclusions: Frameless IGRS provides comparable dosimetric and clinical outcomes to frame-based SRS in a noninvasive fashion for patients with medically refractory $\mathrm{TN}$.
\end{abstract}

Key Words: Frameless, image-guided radiosurgery, radiation, stereotactic radiosurgery, trigeminal neuralgia

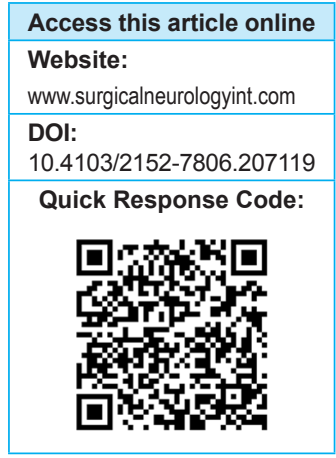

\section{INTRODUCTION}

Trigeminal neuralgia (TN) causes brief and severe intensity unilateral facial pain that is electric shock-like, shooting, stabbing, or sharp in quality. ${ }^{[15]}$ It occurs in one or more divisions of the trigeminal nerve, and there is no clinically evident neurological deficit. ${ }^{[15]}$ Most cases of $\mathrm{TN}$ are produced by compression of the trigeminal nerve root within a few millimeters of entry into the pons, specifically the root entry zone. ${ }^{[20]}$ Painful triggers include
This is an open access article distributed under the terms of the Creative Commons Attribution-NonCommercial-ShareAlike 3.0 License, which allows others to remix, tweak, and build upon the work non-commercially, as long as the author is credited and the new creations are licensed under the identical terms.

For reprints contact: reprints@medknow.com

How to cite this article: Shields LB, Shanks TS, Shearer AJ, Shelton LA, Shelton BJ, Howe J, et al. Frameless image-guided radiosurgery for trigeminal neuralgia. Surg Neurol Int 2017;8:87.

http://surgicalneurologyint.com/Frameless-image-guided-radiosurgery-fortrigeminal-neuralgia/ 
chewing, brushing the teeth, wind on the face, or touching the face. It is more common in people $>50$ years and often affects women more than men. ${ }^{[23]}$ The incidence of $\mathrm{TN}$ is approximately 5 new cases per 100,000 people annually. ${ }^{[9]}$ Several schemes have been developed for the classification of trigeminal neuralgia, including the Barrow Neurological Institute (BNI) scoring system and the Burchiel classification scheme. ${ }^{[11,27]}$

The initial treatment of $\mathrm{TN}$ includes medical management with anticonvulsants and other medications, which are typically used for neuropathic pain. Approximately $90 \%$ of patients with new-onset TN attain either complete or significant relief of symptoms following medical therapy. ${ }^{[23]}$ While TN has been treated with invasive surgical techniques such as microvascular decompression, ${ }^{[25,28,36]}$ radiofrequency rhizotomy, ${ }^{[3]}$ and balloon compression, ${ }^{[2,17,31]}$ stereotactic radiosurgery (SRS) has proven successful with its zero mortality and low morbidity. ${ }^{[29]}$ However, radiosurgery has a lower likelihood of complete pain relief and a higher likelihood of pain recurrence compared with either microvascular decompression or percutaneous rhizotomy. ${ }^{[8]}$ In 1951, Leksell reported the initial use of SRS for the treatment of TN. ${ }^{[19]}$ Utilizing an orthovoltage X-ray machine and stereotactic localization, this method offered long-lasting pain relief without complications in two patients.

Traditional SRS treatment of $\mathrm{TN}$ has used a rigid invasive headframe to deliver between 80-90 Gy to a point within millimeters of the brainstem. We conducted a retrospective study of 20 patients who underwent frameless image-guided radiosurgery (IGRS) by treating a point along the trigeminal nerve ranging from the dorsal root entry (DRE) zone to the retro Gasserian ganglion. This approach ensured submillimeter accuracy and allowed more complicated SRS planning over several days. We present our clinical findings and patient positioning data pertaining to the use of frameless IGRS using the BrainLAB Novalis ExacTrac system (BrainLAB AG, Feldkirchen, Germany) in the treatment of TN. The present study also compares the patient responses following the treatment for $\mathrm{TN}$ with frameless IGRS to frame-based linear accelerator (LINAC) SRS based on historical published data.

\section{MATERIAL AND METHODS}

\section{Patient population}

Between March 2012 and December 2013, a total of 20 individuals with TN underwent frameless IGRS at our institution. The Institutional Review Board approved the retrospective review of these cases. The primary characteristics of these patients are presented in Table 1. The median age was 73 years (range 52-85); there were 8 males and 12 females. All patients were treated with medical therapy (e.g., carbamazepine, gabapentin, or
Table 1: Improvement in pain scores from the baseline to the last follow-up of trigeminal neuralgia patients

\begin{tabular}{|c|c|c|c|}
\hline \multirow[t]{2}{*}{ Covariates } & \multirow[t]{2}{*}{$N(\%)$} & \multicolumn{2}{|l|}{ Univariate Model } \\
\hline & & $\begin{array}{c}\text { Adjusted Odds Ratio } \\
(95 \% \mathrm{Cl})\end{array}$ & $P$ \\
\hline \multicolumn{4}{|l|}{ Gender } \\
\hline Male & $8(40)$ & Reference & \\
\hline Female & $12(60)$ & $1.20[0.231,6.218]$ & 0.8290 \\
\hline \multicolumn{4}{|l|}{ Ever Smoke } \\
\hline Yes & $10(50)$ & $3.235[0.60,17.48]$ & 0.1726 \\
\hline No & $10(50)$ & Reference & \\
\hline \multicolumn{4}{|l|}{ Hypertension } \\
\hline Yes & $11(55)$ & Reference & \\
\hline No & $9(45)$ & $1.324[0.261,6.723]$ & 0.7350 \\
\hline \multicolumn{4}{|l|}{ BMI } \\
\hline$<25$ & $6(30)$ & Reference & \\
\hline $25-30$ & $8(40)$ & $1.268[0.18,8.90]$ & 0.8113 \\
\hline$>30$ & $6(30)$ & $1.000[0.125,8.00]$ & 0.9999 \\
\hline \multicolumn{4}{|l|}{ Diabetes } \\
\hline Yes & $5(25)$ & Reference & \\
\hline No & $15(75)$ & $2.133[0.321,14.16]$ & 0.4327 \\
\hline \multicolumn{4}{|l|}{ Hyperlipidemia } \\
\hline Yes & $10(50)$ & $1.268[0.252,6.372]$ & 0.7735 \\
\hline No & $10(50)$ & Reference & \\
\hline \multicolumn{4}{|l|}{ Previous procedure for TN } \\
\hline Yes & $4(20)$ & Reference & \\
\hline No & $16(80)$ & $14.886[1.119,197.953]$ & 0.0408 \\
\hline \multicolumn{4}{|l|}{ Laterality } \\
\hline Left & $12(60)$ & Reference & \\
\hline Right & $8(40)$ & $12.894[1.665,99.837]$ & 0.0144 \\
\hline \multicolumn{4}{|l|}{ Distribution/Division } \\
\hline 1 (V1; V1, V2; V1, V2, V3) & $5(25)$ & Reference & \\
\hline 2 (V2; V2, V3; V3) & $15(75)$ & $1.158[0.180,7.446]$ & 0.8773 \\
\hline
\end{tabular}

baclofen) prior to the frameless IGRS. Four patients underwent a procedure for $\mathrm{TN}$ at another institution prior to the frameless IGRS: (1) One underwent a rhizotomy 4 months before the SRS; (2) another had a microvascular decompression followed by two rhizotomies within 28 months before the frameless IGRS; (3) one had 3 gamma knife procedures, a microvascular decompression, and a rhizotomy within a 12-year period before the frameless IGRS; and (4) another underwent 2 balloon rhizotomies before the frameless IGRS. Table 1 also highlights the lateralization of the $\mathrm{TN}$, the division of the TN affected, and other comorbidities. One patient was diagnosed with multiple sclerosis. The median body mass index (BMI) of the patients was 27.1 (range 17.2-41.0).

All 20 patients were evaluated by a neurosurgeon, neurologist, and radiation oncologist and underwent frameless IGRS treatment. One patient underwent frameless IGRS retreatment after failing the first 
treatment. Each patient was scored pre- and post- frameless IGRS based on the Barrow Neurological Institute (BNI) pain intensity scoring criteria (I: no pain; II: occasional pain, not requiring medication; III: some pain, controlled with medication; IV: some pain, not controlled with medication; V: severe pain/no pain relief). ${ }^{[6,27]}$ All patients had a BNI of either IV or $\mathrm{V}$ prior to the initial frameless IGRS procedure.

\section{Treatment method}

\section{Simulation}

After each patient signed the informed consent, a bivalve-style thermoplastic mask was fabricated to immobilize the head. All patients were simulated and treated supine and head-first. Next, a stereotactic localizer frame was attached to the imaging frame, and then patients underwent a $0.6 \mathrm{~mm}$ axial slice computed tomography (CT) scan using 40-slice Siemens Sensation Open (Siemens, Munich, Germany) from the vertex to the third cervical vertebra. We obtained a $0.5 \mathrm{~mm}$ constructive interference in a steady state (CISS) T2 magnetic resonance imaging (MRI) sequence using a three Tesla magnet with zero gantry tilt and registered the CT and MRI datasets using BrainLAB iPlan RT Image software, versions 4.1.0 and 4.1.1 [Figure 1].

\section{Treatment planning}

The affected side trigeminal nerve and organs at risk were contoured by the neurosurgeon and radiation oncologist on the fused dataset. The isocenter was placed in the retrogaussarian space. The SRS plan was prescribed at the isocenter, and all plans used between seven and nine non-coplanar arcs with fixed diameter cones ranging from 4.0 to $7.5 \mathrm{~mm}$ aperture, with total scatter factors of 0.669 and 0.815 , respectively. Each arc used between 60 and 140 degrees. The mean maximum brainstem dose was 31 Gy (range 8-57 Gy), the mean dose to $0.1 \mathrm{cc}$ of the brainstem was 9 Gy (range 4-15 Gy), and the mean dose to $1 \mathrm{cc}$ of the brainstem was 3 Gy (range $1-6$ Gy).

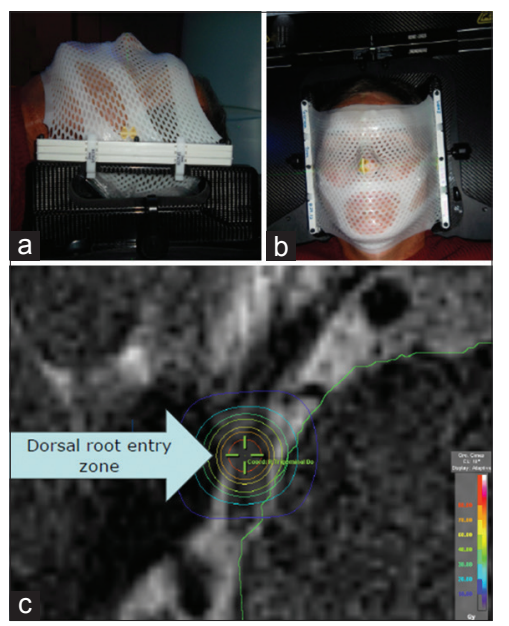

Figure I: (a and b) Thermoplastic mask used for patient immobilization. (c) The CISS MR utilized for target definition. The arrow depicts the dorsal root entry zone
Treatment delivery

Patients were placed in the simulation position on the LINAC treatment couch and the immobilization mask was applied. An optical tracking array for localization was used to determine the initial position. Stereoscopic X-rays were fused with the digitally reconstructed radiographs from simulation, allowing Exactrac to measure the shift from simulation to treatment. Corrections to patient positioning were made for deviations exceeding $0.5 \mathrm{~mm}$ and $1^{\circ}$ using a robotic couch with six degrees of freedom. The mean setup uncertainty from simulation to treatment was $2.9 \mathrm{~mm}( \pm 1.5 \mathrm{~mm})$. Before each arc was delivered, an additional set of stereoscopic X-rays was obtained. Total treatment time ranged from 35 to 100 minutes. Three patients received $80 \mathrm{~Gy}$, and 16 received 85 Gy. One patient was scheduled to receive $85 \mathrm{~Gy}$, however, he experienced severe postnasal drip coupled with claustrophobia and was treated with 22.65 Gy.

\section{Quality assurance}

There were both LINAC and patient specific quality assurance measures taken to maximize the accuracy of treatment. The cones were commissioned with small-field dosimetry techniques for treatment planning. Immediately prior to treatment delivery, a Winston-Lutz test was performed to verify that the treatment and imaging isocenter were congruent. The resulting root-mean square geometric error was $0.58 \pm 0.2 \mathrm{~mm}$.

\section{Follow-up}

Patients were assessed 1 month after the procedure and then approximately every 2 to 3 months. Each patient was evaluated by the treating neurosurgeon and/or radiation oncologist. A physical examination with facial sensation was performed, and a BNI score was assigned.

\section{Data analysis}

Primary data analyses were focused on assessing the outcome of change in BNI score from study entry to BNI measured at the last follow-up. This score ranged from -1 (change from 4 to a 5 in 1 patient) to a 4 (in 3 patients going from a 5 down to a 1). This score change variable was used to create 3 categories of pain improvement: score change of 3 or $4=$ marked improvement ( $n=7$ patients), score change of $2=$ moderate improvement $(n=7$ patients $)$, and score change of $-\mathrm{l}$ or $\mathrm{l}=$ some/none/worse improvement $(n=6)$. This 3 -level ordinal variable was then used as the outcome to assess whether variations in the outcome were due to clinical factors as determined by a proportional odds model using Statistical Analysis Software (SAS) V9.3. The proportional odds assumption was assessed using the score test and was not rejected for any of the covariates examined [Table 1] effectively leading to one odds ratio estimate that succinctly described marked or moderate improvement compared to some/none/worse improvement. Model goodness of fit 
was assessed using the deviance Chi-square statistic, and was found to be adequate for each univariate model that was fit.

Descriptive analyses for the outcome and relevant covariates are reported as frequencies and percentage [Table 1]. Univariate model results are reported as odds ratio (OR) and 95\% confidence limit $(95 \% \mathrm{CI})$ as well as the $P$ value [Table 1].

\section{RESULTS}

Between March 2012 and December 2013, a total of 20 patients (12 women and 8 men) diagnosed with TN underwent frameless IGRS [Table 1]. The median age was 73 years (range 52-85 years). Twelve (60\%) patients were treated for left-sided pain, and $8(40 \%)$ had right-sided pain. The most common distribution of pain was V2 only (8 patients; 40\%), followed by V2-V3 (6 patients; 30\%), Vl only (3 patients; 15\%), and equal numbers of V3 only, V1-V2, and V1-V2-V3 (1 patient each; 5\%). The median follow-up for the 20 patients was 32 months (range 21.6-41.2 months).

\section{Intraprocedural positioning}

Following initial alignment, repeat X-rays were performed during the treatment delivery to verify that the patient position was maintained. The mean intrafraction shift was $0.43 \mathrm{~mm}(0.28-0.76 \mathrm{~mm})$, and the maximum intrafraction shift was $0.95 \mathrm{~mm}(0.53-1.99 \mathrm{~mm})$ [Figure 2]. Rotational errors greater than 1 degree required correction with repositioning using the automated couch corrections and confirmatory stereoscopic X-rays.

\section{Outcomes}

With a median follow-up of 32 months, the response to the frameless IGRS treatment was based on the BNI score determined at follow-up appointments

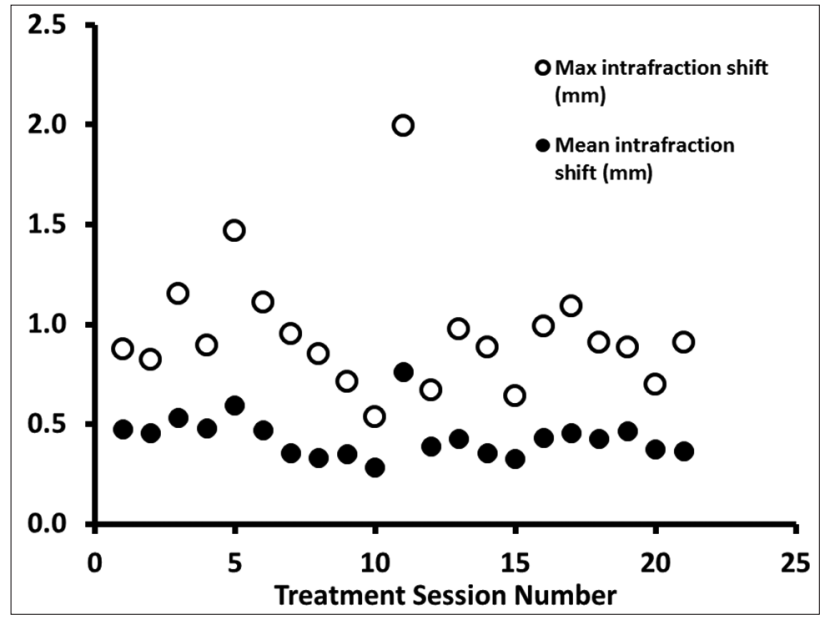

Figure 2: Monitoring of the intrafraction motion during frameless IGRS. The mean intrafraction shift was $0.43 \mathrm{~mm}$, and the mean maximum intrafraction shift was $0.95 \mathrm{~mm}$ with the neurosurgeon and/or radiation oncologist. Good-to-excellent results were defined as a BNI score of I-III. Of the 20 patients who underwent frameless IGRS evaluated at their last follow-up, l (5\%) patient had a post SRS BNI score of $\mathrm{V}$ due to failure of the frameless IGRS procedure. Eleven (55\%) patients had a BNI of III as they continued to consume their TN medications following frameless SRS. One patient had occasional pain without needing medication and, therefore, was a BNI II. Seven (35\%) patients scored a BNI of I as they had attained complete improvement of their symptoms and had discontinued all medications for TN. Thus, $19(95 \%)$ of the 20 patients had a BNI of III or less at last follow-up.

The qualitative change in BNI score was marked in 7 (35\%) patients, moderate in 7 (35\%), and some/none/worse in $6(30 \%)$ patients. A univariate analysis was performed to determine if any clinical factors were associated with outcomes from SRS [Table 1]. Patients who did not have a prior surgery had increased odds for marked or moderate improvement compared to some/none/worse improvement by 14.9 times $(P=0.0408)$ compared to having had prior surgery. Having $\mathrm{TN}$ on the left side was associated with a 12.9 times $(P=0.0144)$ greater odds compared to the right side of either marked or moderate improvement compared to some/none/worse improvement in pain. Covariates having no effect on the odds for improvement include gender, smoking status, hypertension, BMI, diabetes status, hyperlipidemia status, and distribution/division (all $P>0.05$ ).

\section{Complications}

No complications were reported by the $\mathrm{TN}$ patients. Physical examination performed by the neurosurgeon following the frameless IGRS procedure detected no new sensation or motor abnormalities.

\section{Salvage treatments}

Six patients required a salvage procedure after the frameless IGRS. Two underwent an MVD after the frameless IGRS. The first patient underwent the MVD 1 month after the frameless IGRS and attained complete pain relief 7 months after the MVD. Nine months later, he experienced a recurrence of his facial pain requiring medications. He continued to consume medications at the last follow-up 12 months later. Of note, this patient had undergone a rhizotomy prior to the frameless IGRS. Another patient underwent an MVD 13 months after the frameless IGRS and had complete pain relief 1 month later. One patient underwent a second frameless IGRS 5 months after the first one, receiving 85 Gy at each procedure. He experienced complete pain relief 2 months later. Another patient had a rhizotomy 10 months after the initial frameless IGRS and continued to require antiepileptic medications at last follow-up 22 months later. One patient underwent a rhizotomy 39 months 
after the initial frameless IGRS. Interestingly, this patient had undergone two rhizotomies and one MVD prior to the frameless IGRS. The final patient experienced increased pain following the frameless IGRS procedure and was treated with an increased dosage of antiepileptic medications.

The two additional patients who underwent a procedure for TN prior to the frameless IGRS were both assigned a BNI of III at the last follow-up indicating that they continued to consume TN medications.

\section{DISCUSSION}

Since the advent of SRS techniques in the treatment of $\mathrm{TN}$, the most common method utilized has been the gamma knife procedure. ${ }^{[10,14,21,22]}$ Studies have shown that $77-95 \%$ of patients treated with gamma knife SRS have attained a benefit of at least a $50 \%$ reduction of pain. ${ }^{[4,16,22,27]}$ LINAC SRS has emerged as a precise, effective, and noninvasive procedure for the treatment of TN. ${ }^{[2,32]}$ LINAC SRS is dedicated for targeting within the central nervous system and offers stereotactically-guided irradiation to the trigeminal nerve. ${ }^{[29]}$

The majority of LINAC SRS studies for TN have used a frame-based system with either a Novalis, Varian, or Primus device, ${ }^{[7,12,13,18,24,26,29,30,35]}$ whereas a few have reported the innovative frameless technique. ${ }^{[1,8]}$ Table 2 highlights myriad studies in the literature that utilized a linear accelerator SRS for the treatment of TN. Our study corresponds with previous studies in that the patients with $\mathrm{TN}$ failed to respond to previous medical therapy. The vast majority of patients attained either a good or excellent response to the treatment. The mean time to pain relief was approximately 4-8 weeks in most of the studies. The present study concurs with others that LINAC SRS is an effective and noninvasive treatment for patients with $\mathrm{TN}$, especially in the older population. The median ages of the patients ranged 52-85 years; the median age in the present study was
73 years. It has been suggested that radiosurgery is an appealing option for older patients whose condition is not receptive to invasive surgical procedures. ${ }^{[29]}$ LINAC SRS has proven successful, especially in patients who have not had a previous invasive treatment. ${ }^{[18]}$ In their study of prognostic factors for radiosurgery treatment of $\mathrm{TN}$, Chen et al. noted that sensitivity to anticonvulsant medication was the single most important prognostic indicator of treatment success for patients presenting with facial pain. ${ }^{[7]}$ In the present study, patients who did not undergo prior surgery for TN had a higher odds ratio for marked or moderate pain relief compared to patients who had prior surgery $(14.9, P=0.0408)$. In addition, patients who had right-sided $\mathrm{TN}$ had a higher odds ratio for marked or moderate improvement compared to those who had right-sided TN $(12.9, P=0.0144)$. We found a significant difference that patients who underwent a prior procedure for TN had better outcomes. Coincidentally, all the patients with prior procedures had left-sided (4 of 12 patients) TN and did worse. It is likely that the difference in outcome based on laterality is confounded by prior procedures.

Frameless radiosurgery has recently gained in popularity because it is a true noninvasive procedure without the need for anesthetics and sterile processing. ${ }^{[8]}$ In addition, the frameless system avoids patient discomfort associated with frame application and is able to treat extracranial lesions. ${ }^{[5]}$ The frameless approach corrects for positioning errors automatically due to the imaging guidance during the procedure. ${ }^{[8]}$ The imaging, planning, and treatment components may be performed in different sessions. In this respect, frameless SRS is valuable in developing more complicated SRS planning over a several day period. Studies utilizing a head phantom have shown that intrafraction motion in the BrainLab frameless mask is minimal ${ }^{[33]}$ and that this innovative technique is valuable in treating intracranial benign and malignant lesions. ${ }^{[34]}$

Frameless IGRS has rarely been used to treat TN. ${ }^{[8]}$ Chen et al. performed a study of 44 patients who

Table 2: SRS using linear accelerator for the treatment of trigeminal neuralgia

\begin{tabular}{|c|c|c|c|c|}
\hline Study & $N$ & Dose/Device & $\begin{array}{l}\text { Follow-Up } \\
\text { (Months) }\end{array}$ & $\begin{array}{c}\% \text { Good or Excellent } \\
\text { response }\end{array}$ \\
\hline Goss et al. 2003 & 25 & 90 Gy/Novalis & $18(8-52)$ & 100 \\
\hline Frighetto et al. 2004 & 22 & 70-90 Gy/Novalis & $21.2(8-52)$ & 95.4 \\
\hline Kubicek et al. 2004 & 20 (23 treatments) & 82.3-100 Gy/Varian & 56.5 & 78 \\
\hline Richards et al. 2005 & 28 & 80 Gy/Narian & $12(1-40)$ & 75 \\
\hline Pusztaszeri et al. 2007 & 17 & 40-56 Gy/Primus & $12(1-60)$ & 100 \\
\hline Chen et al. 2010 & 44 & 90 Gy/Novalis* & 15 & 91 \\
\hline Chen et al. 2008 & 82 & $85-90 \mathrm{~Gy} /$ Novalis & 18 & 85.3 \\
\hline Zahra et al. 2009 & 20 & $90 \mathrm{~Gy} /$ Novalis & 14.2 & 95 \\
\hline Smith et al. 2011 & 179 & 70-90 Gy/ & $28.8(5-142)$ & 79.3 \\
\hline Current Study 2017 & 20 (21 treatments) & 80-85 Gy/Novalis* & 32 & 95 \\
\hline
\end{tabular}

*Indicates frameless image-guided radiosurgery using Novalis linear accelerator with ExacTrac 
were treated with frameless IGRS over an 18-month period. ${ }^{[8]}$ The isocenter dose of 90 Gy was delivered via a 4-mm collimator. The median age of patients was 65 years, and their BNI scores were IV or V prior to the procedure. Before the day of the treatment, the patients underwent high-resolution MRI with a $1.0 \mathrm{~mm}$ slice thickness. The overall intrafraction positioning error was $0.49 \pm 0.44 \mathrm{~mm}$, and the median time to pain relief was 4 weeks. A total of $40(91 \%)$ patients attained a BNI score of III or better, whereas 19 (43\%) patients achieved a BNI score of I.

The findings of the present study concur with those of Chen et al. using frameless IGRS to treat patients with TN. ${ }^{[8]}$ Our patient population was slightly older than those of Chen et al. (73 vs 65 years), while the BNI scores in both studies were either IV or V prior to the procedure. The MRIs in our study were performed with a $0.6 \mathrm{~mm}$ slice thickness which allowed better visualization of the area and greater precision in treatment compared to the work of Chen et al. who used a $1.0 \mathrm{~mm}$ slice thickness. The mean intrafraction shift in our study was $0.43 \mathrm{~mm}$ compared to $0.49 \mathrm{~mm}$ in theirs. Nineteen $(95 \%)$ patients received a BNI score of III or better following frameless IGRS in the current study, and $8(40 \%)$ patients attained complete pain relief with a BNI score of I.

\section{CONCLUSION}

The present study describes our initial experience with treatment of TN using a frameless IGRS procedure in a multidisciplinary setting. Our data suggest that it is an effective and noninvasive method of treating $\mathrm{TN}$, especially in older individuals who are refractory to medical management. The slice thickness of $0.6 \mathrm{~mm}$ provided increased resolution at the target compared to previous studies in the literature. This small thickness coupled with the mapping of the patient's movement during treatment allowed us to have a greater confidence to perform frameless IGRS. Further investigation is warranted with a larger sample size to confirm the efficacy of frameless IGRS for TN.

\section{Acknowledgment}

We acknowledge Norton Healthcare for their continued support.

\section{Financial support and sponsorship Nil.}

\section{Conflicts of interest}

There are no conflicts of interest.

\section{REFERENCES}

I. Bale RJ, Laimer I, Martin A, Schlager A, Mayr C, Rieger M, et al. Frameless stereotactic cannulation of the foramen ovale for ablative treatment of trigeminal neuralgia. Neurosurgery 2006;59(4 Suppl 2):ONS394-ONS40I.
2. Bergenheim AT, Asplund P, Linderoth B. Percutaneous retrogasserian balloon compression for trigeminal neuralgia: Review of critical technical details and outcomes. World Neurosurg 2013;79:359-68.

3. Bozkurt M, Al-Beyati ES, Ozdemir M, Kahilogullari G, Elhan AH, Savas A, et al. Management of bilateral trigeminal neuralgia with trigeminal radiofrequency rhizotomy: A treatment strategy for the life-long disease. Acta Neurochir 20|2;|54:785-9|.

4. Brisman R. Gamma knife radiosurgery for primary management for trigeminal neuralgia. J Neurosurg 2000;93(Suppl 3):I59-61.

5. Chang SD, Main W, Martin DP, Gibbs IC, Heilbrun MP. An analysis of the accuracy of the CyberKnife: A robotic frameless stereotactic radiosurgical system. Neurosurgery 2003;52:140-6.

6. Chen HI, Lee JY. The measurement of pain in patients with trigeminal neuralgia. Clin Neurosurg 2010;57:129-33.

7. Chen JC, Greathouse HE, Girvigian MR, Miller MJ, Liu A, Rahimian J. Prognostic factors for radiosurgery treatment of trigeminal neuralgia. Neurosurgery 2008;62(5 Suppl):A53-A60.

8. Chen JC, Rahimian J, Rahimian R, Arellano A, Miller MJ, Girvigian MR. Frameless image-guided radiosurgery for initial treatment of typical trigeminal neuralgia. World Neurosurg 2010;74:538-43.

9. Dos Santos MA, Perez de Salcedo JB, Gutierrez Diaz JA, Nagore G, Calvo FA, Samblas J, et al. Outcome for patients with essential trigeminal neuralgia treated with linear accelerator stereotactic radiosurgery. Stereotact Funct Neurosurg 2011;89:220-5.

10. Dvorak T, Finn A, Price LL, Mignano JE, Fitzek MM, Wu JK, et al. Retreatment of trigeminal neuralgia with Gamma Knife radiosurgery: Is there an appropriate cumulative dose? Clinical article. J Neurosurg 2009; I I 1:359-64.

II. Eller JL, Raslan AM, Burchiel KJ. Trigeminal neuralgia: Definition and classification. Neurosurg Focus 2005; I8:E3.

12. Frighetto L, De Salles AA, Smith ZA, Goss B, Selch M, Solberg T. Noninvasive linear accelerator radiosurgery as the primary treatment for trigeminal neuralgia. Neurology 2004;62:660-2.

13. Goss BW, Frighetto L, DeSalles AA, Smith Z, Solberg T, Selch M. Linear accelerator radiosurgery using 90 gray for essential trigeminal neuralgia: Results and dose volume histogram analysis. Neurosurgery 2003;53:823-8.

14. Guo WY, Chu WC, Wu MC, Chung WY, Gwan WP, Lee YL, et al. An evaluation of the accuracy of magnetic-resonance-guided Gamma Knife surgery. Stereotact Funct Neurosurg 1996;66(Suppl I):85-92.

15. Headache Classification Committee of the International Headache Society (IHS). The International Classification of headache Disorders, $3^{\text {rd }}$ edition (beta version). Cephalalgia 2013;33:629-808.

16. Kondziolka D, Lunsford LD, Flickinger JC, Young RF, Vermeulen S, Duma CM, et al. Stereotactic radiosurgery for trigeminal neuralgia: A multiinstitutional study using the gamma unit. J Neurosurg 1996;84:940-5.

17. Kouzounias K, Schechtmann G, Lind G, Winter J, Linderoth B. Factors that influence outcome of percutaneous balloon compression in the treatment of trigeminal neuralgia. Neurosurgery 2010;67:925-34.

18. Kubicek GJ, Hall WA, Orner JB, Gerbi BJ, Dusenbery KE. Long-term follow-up of trigeminal neuralgia treatment using a linear accelerator. Stereotact Funct Neurosurg 2004;82:244-9.

19. Leksell L. Sterotaxic radiosurgery in trigeminal neuralgia. Acta Chir Scand 1971;137:3| I-4.

20. Love S, Coakham HB. Trigeminal neuralgia: Pathology and pathogenesis. Brain 200I;124(Pt I2):2347-60.

21. Lucas JT, Jr., Nida AM, Isom S, Marshall K, Bourland JD, Laxton AW, et al. Predictive nomogram for the durability of pain relief from gamma knife radiation surgery in the treatment of trigeminal neuralgia. Int J Radiat Oncol Biol Phys 20|4;89:120-6.

22. Marshall K, Chan MD, McCoy TP, Aubuchon AC, Bourland JD, McMullen KP, et al. Predictive variables for the successful treatment of trigeminal neuralgia with gamma knife radiosurgery. Neurosurgery 2012;70:566-72.

23. Pollock BE, Schoeberl KA. Prospective comparison of posterior fossa exploration and stereotactic radiosurgery dorsal root entry zone target as primary surgery for patients with idiopathic trigeminal neuralgia. Neurosurgery 2010;67:633-8.

24. Pusztaszeri M, Villemure JG, Regli L, Do HP, Pica A. Radiosurgery for trigeminal neuralgia using a linear accelerator with BrainLab system: Report on initial experience in Lausanne, Switzerland. Swiss Med Wkly 2007;137:682-6. 
25. Reddy VK, Parker SL, Patrawala SA, Lockney DT, Su PF, Mericle RA. Microvascular decompression for classic trigeminal neuralgia: Determination of minimum clinically important difference in pain improvement for patient reported outcomes. Neurosurgery 2013;72:749-54.

26. Richards GM, Bradley KA, Tome WA, Bentzen SM, Resnick DK, Mehta MP. Linear accelerator radiosurgery for trigeminal neuralgia. Neurosurgery 2005;57:1 193-200

27. Rogers CL, Shetter AG, Fiedler JA, Smith KA, Han PP, Speiser BL. Gamma knife radiosurgery for trigeminal neuralgia: The initial experience of The Barrow Neurological Institute. Int J Radiat Oncol Biol Phys 2000;47: I0I3-9.

28. Sandel T, Eide PK. Long-term results of microvascular decompression for trigeminal neuralgia and hemifacial spasms according to preoperative symptomatology. Acta Neurochir 2013;155:1681-92.

29. Smith ZA, De Salles AA, Frighetto L, Goss B, Lee SP, Selch M, et al. Dedicated linear accelerator radiosurgery for the treatment of trigeminal neuralgia. J Neurosurg 2003;99:5I I-6.

30. Smith ZA, Gorgulho AA, Bezrukiy N, McArthur D, Agazaryan N, Selch MT, et al. Dedicated linear accelerator radiosurgery for trigeminal neuralgia: A single-center experience in 179 patients with varied dose prescriptions and treatment plans. Int J Radiat Oncol Biol Phys 20I I;8I:225-3I.

3I. Stomal-Slowinska M, Slowinski J, Lee TK, Uitti RJ, Deen HG, Reimer R, et al. Correlation of clinical findings and results of percutaneous balloon compression for patients with trigeminal neuralgia. Clin Neurol Neurosurg 20 I I; I I 3: I4-2 I.

32. Varela-Lema L, Lopez-Garcia M, Maceira-Rozas M, Munoz-Garzon V. Linear accelerator stereotactic radiosurgery for trigeminal neuralgia. Pain Physician 20I5; | $8: 15-27$

33. Verbakel WF, Lagerwaard FJ, Verduin AJ, Heukelom S, Slotman BJ, Cuijpers JP. The accuracy of frameless stereotactic intracranial radiosurgery Radiother Oncol 2010;97:390-4.

34. Wurm RE, Erbel S, Schwenkert I, Gum F, Agaoglu D, Schild R, et al. Novalis frameless image-guided noninvasive radiosurgery: Initial experience. Neurosurgery 2008;62(5 Suppl):AI I-AI7.

35. Zahra H, Teh BS, Paulino AC, Yoshor D, Trask T, Baskin D, et al. Stereotactic radiosurgery for trigeminal neuralgia utilizing the BrainLAB Novalis system. Technol Cancer Res Treat 2009;8:407-I2.

36. Zhang H, Lei D, You C, Mao BY, Wu B, Fang Y. The long-term outcome predictors of pure microvascular decompression for primary trigeminal neuralgia. World Neurosurg 2013;79:756-62. 